Field Research Center

Oak Ridge, Tennessee

Quality Assurance Plan for Field Activities at the Natural and Accelerated Bioremediation Research (NABIR) Field Research Center (FRC), Oak Ridge, Tennessee

December 2001

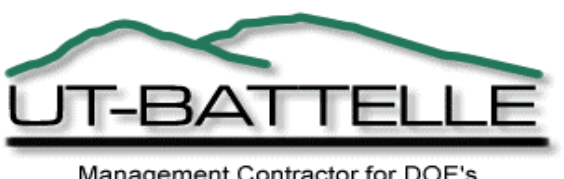




\section{DOCUMENT AVAILABILITY}

Reports produced after January 1, 1996, are generally available free via the U.S. Department of Energy (DOE) Information Bridge.

Web site http://www.osti.gov/bridge

Reports produced before January 1,1996, may be purchased by members of the public from the following source.

National Technical Information Service

5285 Port Royal Road

Springfield, VA 22161

Telephone 703-605-6000 (1-800-553-6847)

TDD 703-487-4639

Fax 703-605-6900

E-mail info@ntis.fedworld.gov

Web site http://www.ntis.gov/support/ordernowabout.htm

Reports are available to DOE employees, DOE contractors, Energy Technology Data Exchange (ETDE) representatives, and International Nuclear Information System (INIS) representatives from the following source.

Office of Scientific and Technical Information

P.O. Box 62

Oak Ridge, TN 37831

Telephone 865-576-8401

Fax 865-576-5728

E-mail reports@adonis.osti.gov

Web site http://www.osti.gov/contact.html

This report was prepared as an account of work sponsored by an agency of the United States Government. Neither the United States Government nor any agency thereof, nor any of their employees, makes any warranty, express or implied, or assumes any legal liability or responsibility for the accuracy, completeness, or usefulness of any information, apparatus, product, or process disclosed, or represents that its use would not infringe privately owned rights. Reference herein to any specific commercial product, process, or service by trade name, trademark, manufacturer, or otherwise, does not necessarily constitute or imply its endorsement, recommendation, or favoring by the United States Government or any agency thereof. The views and opinions of authors expressed herein do not necessarily state or reflect those of the United States Government or any agency thereof. 
Environmental Sciences Division

\title{
QUALITY ASSURANCE PLAN FOR FIELD ACTIVITIES AT THE NATURAL AND ACCELERATED BIOREMEDIATION RESEARCH (NABIR) FIELD RESEARCH CENTER (FRC), OAK RIDGE, TENNESSEE
}

\author{
Craig C. Brandt, Susan K. Holladay, D. B. Watson \\ Environmental Sciences Division \\ Oak Ridge National Laboratory
}

Date Published: December 2001

Prepared for

U.S. Department of Energy

Office of Biological and Environmental Research

Budget Activity Number KP 1301010

Prepared by

OAK RIDGE NATIONAL LABORATORY

Oak Ridge, Tennessee 37831

managed by

UT-BATTELLE, LLC

for the

U.S. DEPARTMENT OF ENERGY

under contract DE-AC05-00OR22725 


\section{CONTENTS}

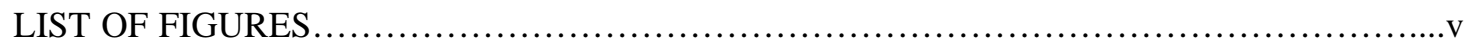

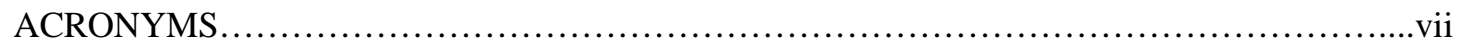

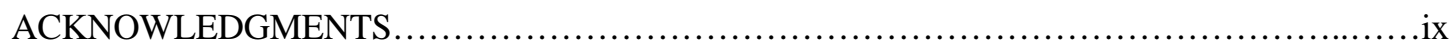

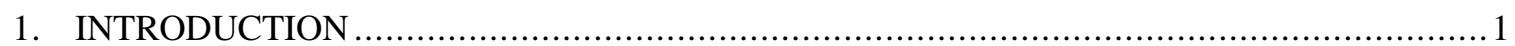

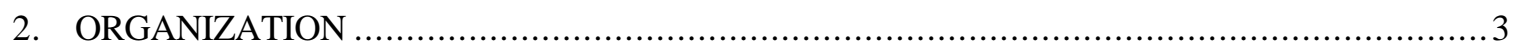

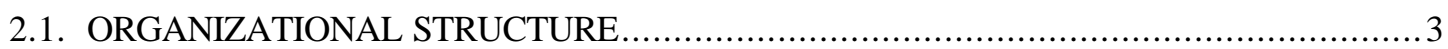

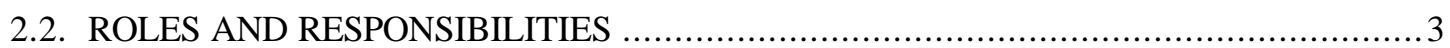

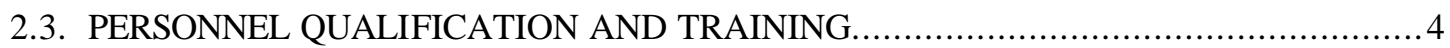

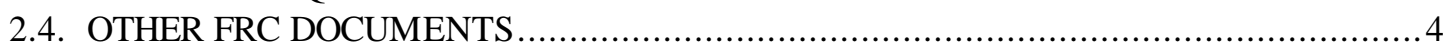

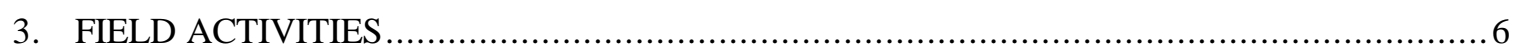

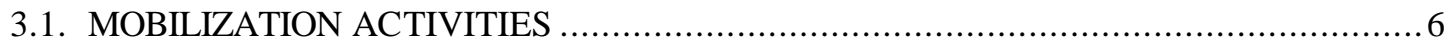

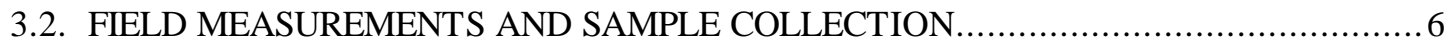

3.3. PROCESSING AND DISTRIBUTION OF FIELD SAMPLES ..................................

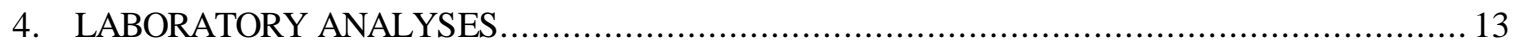

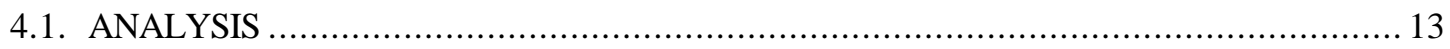

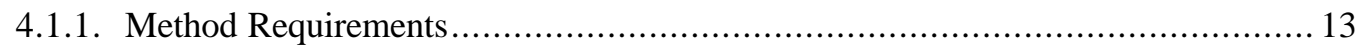

4.1.2. Instrument Calibration and Maintenance................................................. 13

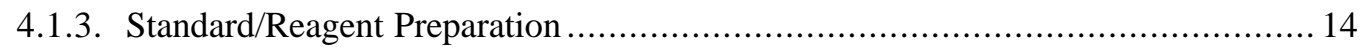

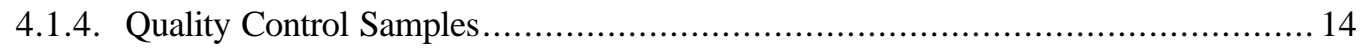

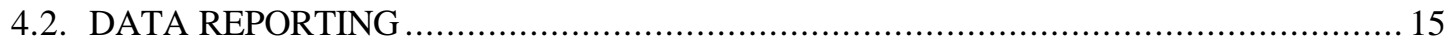

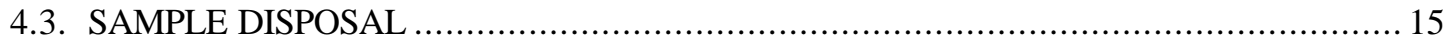

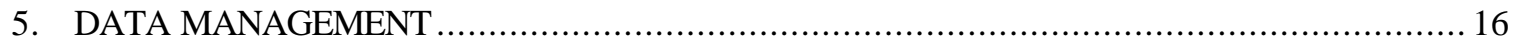

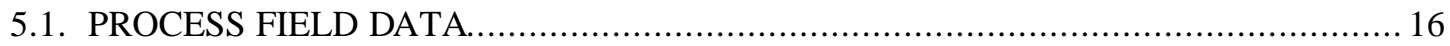

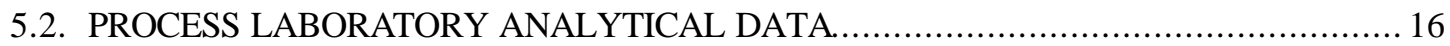

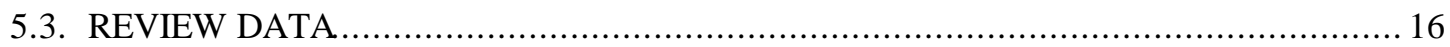

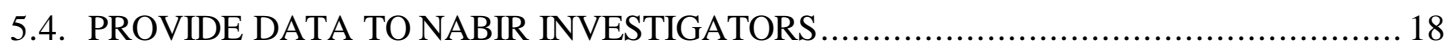

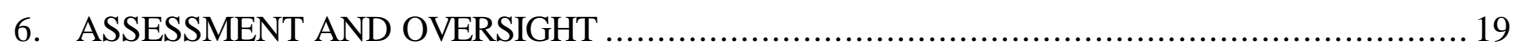

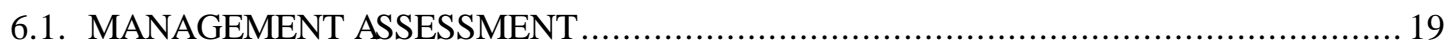

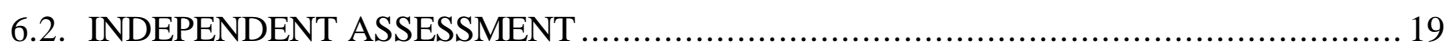

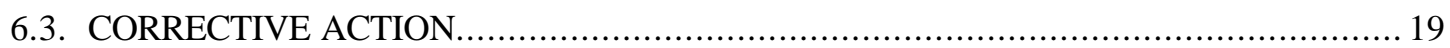

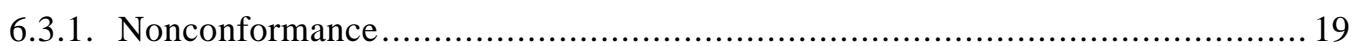

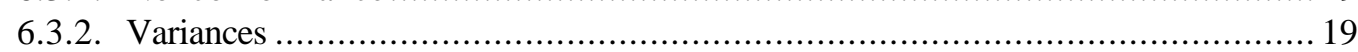

6.4. LABORATORY PERFORMANCE INDICATORS …......................................... 19

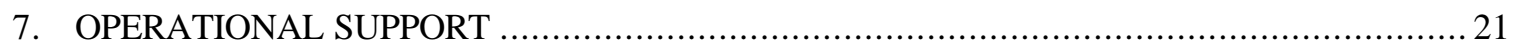

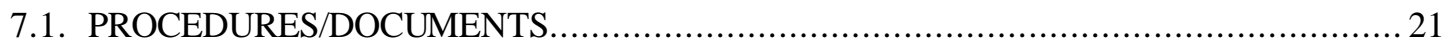

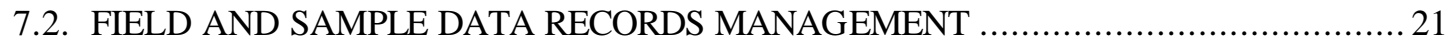

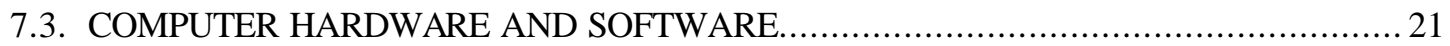

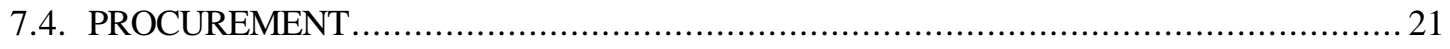

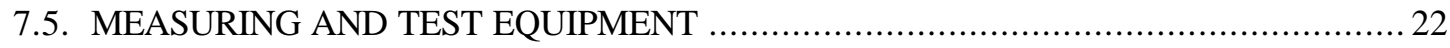

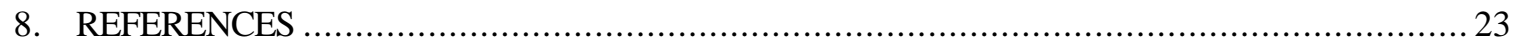





\section{LIST OF FIGURES}

Figure

Page

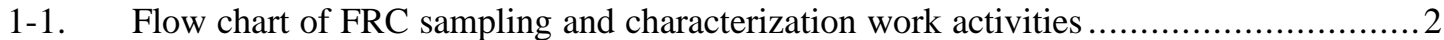

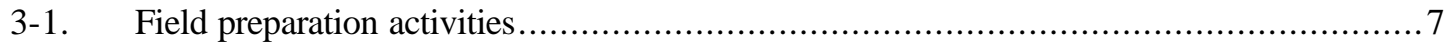

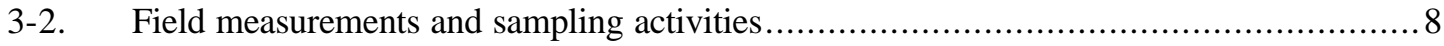

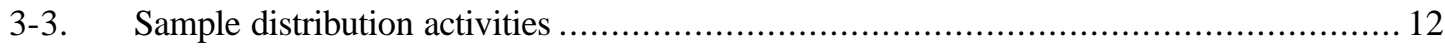

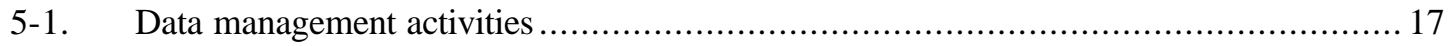





\section{ACRONYMS}

$\begin{array}{ll}\text { DOE } & \text { Department of Energy } \\ \text { DOT } & \text { Department of Transportation } \\ \text { EDD } & \text { Electronic Data Deliverable } \\ \text { ESD } & \text { Environmental Sciences Division } \\ \text { ESH\&Q Environment, Safety, Health, and Quality } \\ \text { FRAP } & \text { Field Research Advisory Panel } \\ \text { FRC } & \text { Field Research Center } \\ \text { HASP } & \text { Health and Safety Plan } \\ \text { ISMS } & \text { Integrated Safety Management System } \\ \text { M\&TE } & \text { Measuring and Testing Equipment } \\ \text { MOT } & \text { Material of Trade } \\ \text { NABIR } & \text { Natural and Accelerated Bioremediation Research } \\ \text { NIST } & \text { National Institute for Standards and Technology } \\ \text { ORNL } & \text { Oak Ridge National Laboratory } \\ \text { QA } & \text { Quality Assurance } \\ \text { QAP } & \text { Quality Assurance Plan } \\ \text { QAS } & \text { Quality Assurance Specialist } \\ \text { QC } & \text { Quality Control } \\ \text { SOW } & \text { Statement of Work } \\ \text { TPM } & \text { Transportation and Packaging Management }\end{array}$





\section{ACKNOWLEDGMENTS}

This research was funded by the Natural and Accelerated Bioremediation Research (NABIR) program, Biological and Environmental Research (BER), U.S. Department of Energy. 


\section{INTRODUCTION}

The Environmental Sciences Division (ESD) at Oak Ridge National Laboratory (ORNL) has established a Natural and Accelerated Bioremediation Research (NABIR) program Field Research Center (FRC) for the U.S. Department of Energy (DOE) Office of Biological and Environmental Research. The FRC is located in Bear Creek Valley within the Y-12 Plant area of responsibility on DOE's Oak Ridge Reservation in Tennessee. The NABIR program is a long-term effort designed to increase the understanding of fundamental biogeochemical processes that would allow the use of bioremediation approaches for cleaning up DOE's contaminated legacy waste sites. The FRC provides a site for investigators in the NABIR program to conduct research and obtain samples related to in situ bioremediation. The FRC is integrated with existing and future laboratory and field research and provides a means of examining the biogeochemical processes that influence bioremediation under controlled smallscale field conditions.

This Quality Assurance Plan (QAP) documents the quality assurance protocols for field and laboratory activities performed by the FRC staff. It supplements the requirements in the ORNL Nuclear Quality Assurance Program and the ESD Quality Assurance Program. The QAP addresses the requirements in Title 10 CFR, Part 830 Subpart A, Quality Assurance Requirements, using a graded approach appropriate for Research and Development projects based on guidance from Implementation Guide for Quality Assurance Programs for Basic and Applied Research (DOE-ER-STD-6001-92). It also supports the NABIR FRC Management Plan (Watson and Quarles 2000a) which outlines the overall procedures, roles and responsibilities for conducting research at the FRC.

The QAP summarizes the organization, work activities, and qualify assurance and quality control protocols that will be used to generate scientifically defensible data at the FRC. The QAP pertains to field measurements and sample collection conducted by the FRC to characterize the site and in support of NABIR-funded investigations at the FRC. NABIR investigators who collect their own samples or measurements at the FRC will be responsible for developing their own data quality assurance protocol. Notably, this QAP will be of direct benefit to NABIR investigators who will be provided with and use the documented quality data about the FRC to support their investigations.

The QAP consists of the following sections:

- Section 2. Organization

- Section 3. Field Activities

- Section 4. Laboratory Analyses

- Section 5. Data Management

- Section 6. Assessment and Oversight

- Section 7. Operational Support

An overall flow chart of the field and laboratory work activities is shown in Figure 1.1. These activities are described in greater detail in Sections 3, 4, and 5. 


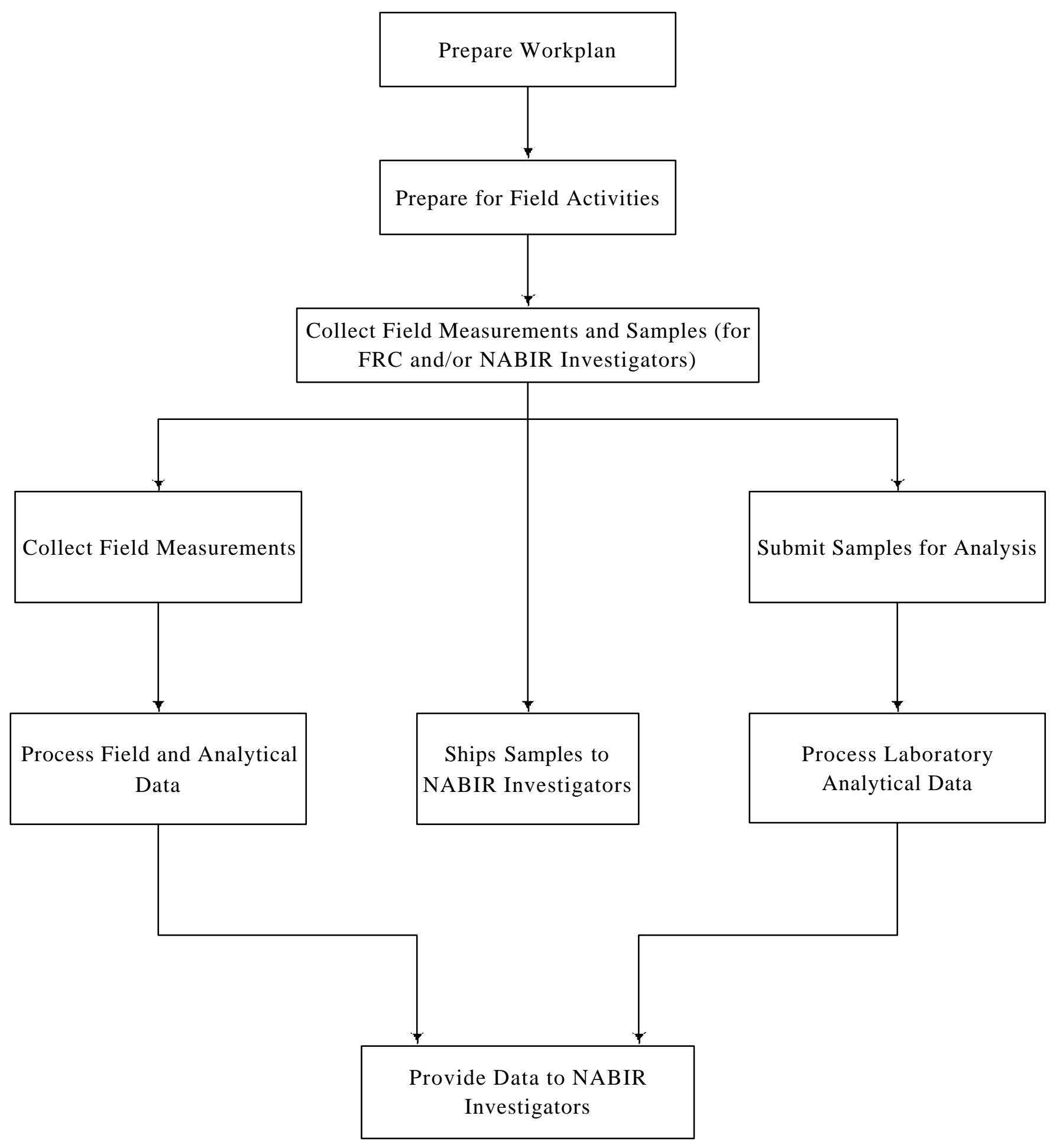

Figure 1.1. Flow chart of FRC sampling and characterization work activities. 


\section{ORGANIZATION}

\subsection{ORGANIZATIONAL STRUCTURE}

ESD has primary responsibility for the operation and management of the FRC at ORNL. Specific responsibilities include conducting site characterization, providing field sampling and analytical support to other NABIR investigators, and ensuring compliance with applicable ORNL, local, state and federal requirements. Additional information about the overall organization of the FRC can be found in the FRC Management Plan (Watson and Quarles 2000a).

\subsection{ROLES AND RESPONSIBILITIES}

The roles and responsibilities of FRC staff involved in assessing and maintaining the quality of data generated at the FRC are described below.

The FRC Manager is responsible for the overall operation of the FRC and implementation of an appropriate quality assurance program for the activities performed by the FRC staff. He or she develops work plans (e.g., site characterization plan) that defines the type and frequency of field sampling and measurements needed to characterize the FRC. The FRC Manager also interacts with other NABIR-funded investigators to determine what samples and measurements must be collected in support of their scientific objectives. The FRC Manager will schedule and oversee all field and laboratory activities related to site characterization and sample collection for other NABIR investigators. He or she coordinates the development of statements of work to procure analytical services from contract laboratories. At various times the FRC Manager may delegate some of these responsibilities to other FRC staff.

The Field Team is responsible for installing the necessary monitoring structures (e.g., groundwater wells) and collecting the field samples and measurements as directed by the FRC Manager and prescribed in the characterization and quality assurance (QA) plans. The Field Team maintains and calibrates equipment, records field data accurately, obtains representative samples as directed by the FRC Manager, preserves the samples as needed, and transfers the samples to the appropriate personnel (i.e. laboratory, storage, or NABIR investigator) as instructed by the FRC Manager.

Various Analytical Laboratories will perform the analyses on the samples collected by the FRC Field Teams. Some of these laboratories will be affiliated with ORNL while others will be external contract laboratories qualified by DOE. Qualification of the ORNL laboratories will be based on successful past performance on other DOE projects. Final approval of the laboratory will rest with the FRC Manager or approved designee. In addition, NABIR-funded investigators may request the FRC to collect samples and measurements in support of their research. Each analytical laboratory is responsible for providing the FRC with data of prescribed quality, running the necessary quality control checks, and maintaining and calibrating equipment. The FRC Manager will approve

the minimum requirements for analysis of NABIR samples for each laboratory that will perform characterization of the site. Screening analyses will be analyzed using a graded approach that will facilitate gathering the information needed to make project decisions. 
The Data Manager is responsible for assembling the FRC-generated field and laboratory data and preparing data sets for distribution via the FRC web page (http://www.esd.ornl.gov/nabirfrc/). He or she is also responsible for tracking the distribution of all samples collected by the Field Team. The Data Manager may also assist NABIR investigators in accessing archived data sets that are too large to place on the web page (e.g., continuous water level data from transducers and data loggers) and relevant historical data for the FRC.

The ESD Quality Assurance Specialist (QAS) serves as a division resource for quality matters. The QAS helps ESD implement its QA program by interpreting requirements within the context of the division's activities. The QAS also interacts with the ORNL Quality Services Division to meet laboratory reporting and other QA requirements.

\subsection{PERSONNEL QUALIFICATION AND TRAINING}

Most FRC staff have degrees in scientific disciplines and work experience that constitute professional qualification. Concern with data quality and individual professional reputation is integral to that background. For technicians, qualification develops from working with experienced supervisors/mentors who initially guide their work. For certain narrowly defined, specific analytical or monitoring activities, more formal performance-based training may be required and implemented. Retraining is done to enhance proficiency and to inform personnel of changes to methods and procedures.

The FRC Manager identifies personnel requiring training and determines the training needed. Training will address any special controls, procedures, test equipment, tools, safety requirements, and other skills or processes that affect quality. The Integrated Safety Management System (ISMS) and the ESD Environment, Safety, Health and Quality (ESH\&Q) Project Evaluation checklist contain specific questions keyed to ORNL procedures and associated requirements. When needed, the FRC staff receives the necessary training, and this activity is documented by attendance sheets, training logs, personnel training records, performance checklists, certificates, exams, and other verifiable documentation of training received. Records are maintained according to the guidance given in Section 7.

\subsection{OTHER FRC DOCUMENTS}

This QAP is one of a set of high-level planning documents developed by FRC staff members that govern the operation of the FRC. Other relevant documents include the following plans:

- Management Plan (Watson and Quarles 2000a), which tiers from the Office of Biological and Environmental Research NABIR Program Plan (DOE 1995) and outlines procedures to facilitate the scientific approach to research at the FRC and the approach to ensuring Environment, Safety and Health compliance;

- Site Characterization Plan (Watson et al. 2000), which describes the site characterization activities to be conducted at the FRC in fiscal years 2000 and 2001;

- Site-Specific Health and Safety Plan (Watson and Quarles 2000b) tiered from the ORNL HAZWOPER Program Manual;

- Communication/Community Interaction Plan (Wolfe et al. 2001) detailing interactions with community and other stakeholder groups. 
Together, these high-level plans form a "road map" for the operation of the FRC. They cover both the scientific research to be conducted, as well as the commitments to environment, safety, and health. Current versions of these documents will be available at the FRC field site, in the FRC library located in ESD and on the FRC web page (http://www.esd.ornl.gov/nabirfrc/).

In addition to these plans, project-specific workplans will be prepared as needed describing each work phase to be conducted at the FRC. These work plans will be prepared by FRC staff members or NABIR investigators depending on the source of project funding and who is responsible for executing the project.

Specific ESH\&Q requirements for projects conducted at the FRC are determined on a project-by-project basis through individual ISMS project reviews conducted in accordance with, and as described in, the FRC Management Plan (Watson and Quarles 2000a). Once project requirements are defined, the NABIR investigator and FRC Manager come to an agreement on how project task responsibilities are divided (e.g., who conducts specific sampling analysis and well installations). The task responsibilities are documented and signed by the NABIR investigator and FRC Manager, and placed in the FRC files.

A Sample Transportation Checklist is completed by FRC staff during the ISMS review for all projects involving transport of samples on public roads. The checklist includes questions about the specific activity of the material, its flashpoint, whether or not it is preserved, if samples contain hazardous materials, if the sample is a Resource Conservation and Recovery Act waste, and whether there is any question about the hazardous nature or radioactivity of the shipment. Based on past experience with sample collection in the Bear Creek Valley, samples collected at the FRC are generally below both the Department of Transportation (DOT) radioactivity limit of 70 $\mathrm{Bq} / \mathrm{g}$, and the limits for transportation of corrosives/preservatives. However, the potential to exceed DOT regulations does exist. Therefore, special provisions for sample transportation are required if DOT regulations are exceeded. Off-site laboratories receiving samples are required to document that they have obtained the necessary approvals to handle anticipated radioactivity and other contaminant levels. 


\section{FIELD ACTIVITIES}

This section provides an overview of the work activities associated with collecting field measurements and samples at the FRC.

\subsection{MOBILIZATION ACTIVITIES}

Field mobilization activities prepare the site for collecting samples and obtaining field measurements (e.g., groundwater levels). Activities include surveying the sites, marking sampling locations, obtaining the necessary permits, installing and inspecting wells, and installing and testing field equipment. Figure 3.1 illustrates the steps involved in preparing for field activities.

The sampling locations and the installation or construction procedures will be designated by the FRC Manager and/or in specific field work plans. The Field Team will assemble the materials necessary to install the monitoring structures. No field activities will be conducted until the FRC Manager has determined that the necessary permits have been obtained, all field personnel are properly trained and qualified to conduct the work, the required equipment is available and functioning properly, and sample identification and data recording requirements are understood.

Once in the field, the Field Team will install the monitoring facilities and record the construction and installation data. Each sampling location will be assigned a unique identifier and this identifier will be associated with all samples collected at the location. Following installation, a site survey will be conducted to obtain the geographic coordinates of the monitoring structure. The coordinate system (e.g., Tennessee State Plane) and the method of determining the geographic coordinates will also be recorded together with the estimated (or true) accuracy. Monitoring structures will be inspected periodically by the Field Team, and the FRC Manager notified if a monitoring structure is no longer operational.

All drilling, construction and survey data will be forwarded to the Data Manager who will assemble the data into a construction event file. The construction data will be computerized and made available via the FRC web page for access by NABIR investigators. Hard copy records will be retained as described in Section 5.

\subsection{FIELD MEASUREMENTS AND SAMPLE COLLECTION}

This phase includes the activities associated with collection of samples and measurements from locations within the study site. The specific activities involved in this phase are shown in Figure 3.2. The FRC Manager will communicate the types and number of samples and measurements to be collected from each location within the study site to FRC staff during planning meetings and/or by electronic mail.

The Data Manager, in conjunction with the FRC Manager, will provide a mechanism for assigning a unique identifier to each sample. Each sample will be labeled with the identifier, location, container type, preservative, and the sampler's initials. An example of a groundwater identifier is FW001-000100 where FW001 is the location identifier and 000100 is the sample number. The labels may be generated prior to fieldwork or completed in the field by the Field Team. 


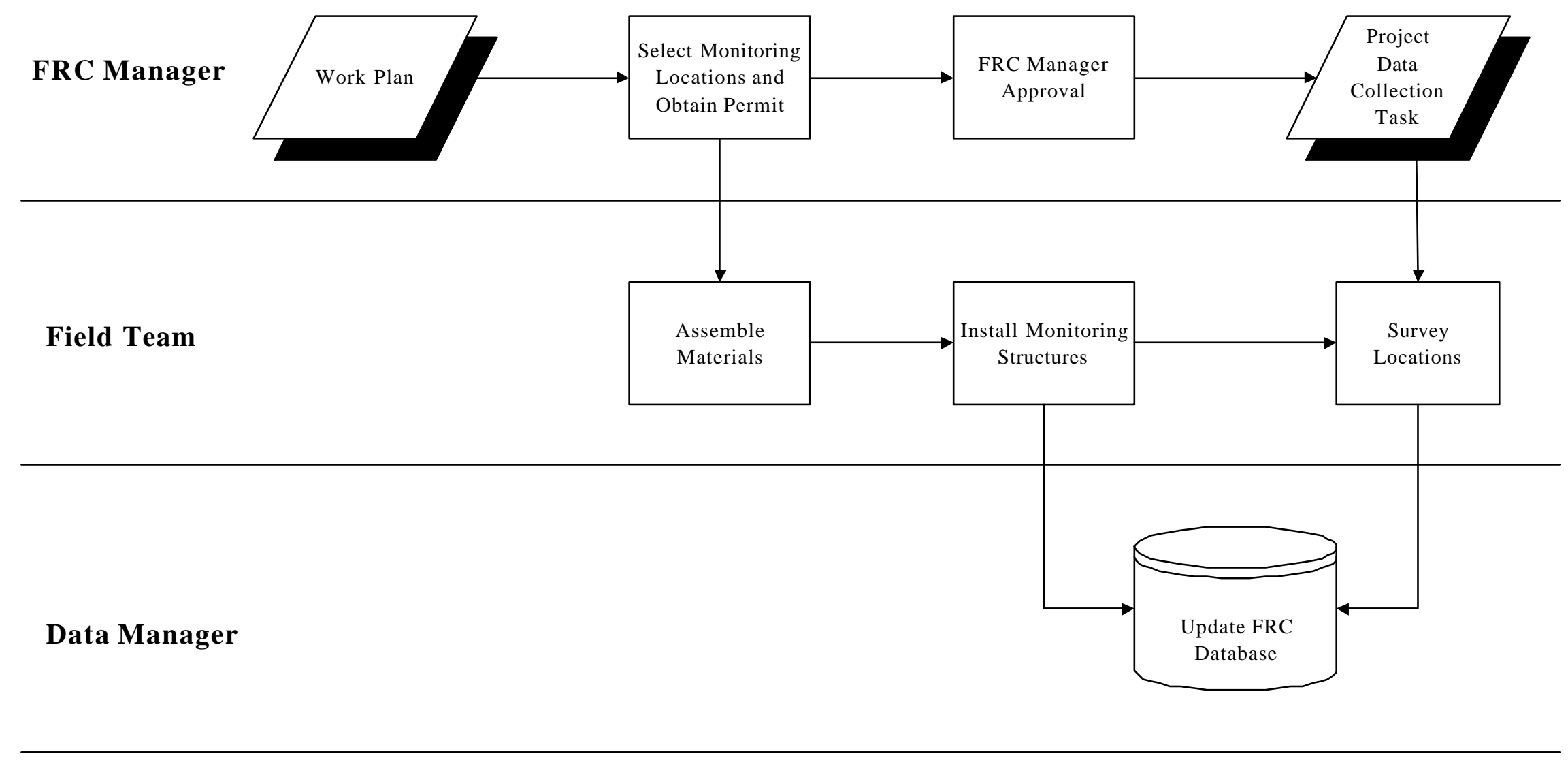

Figure 3.1. Field preparation activities. 


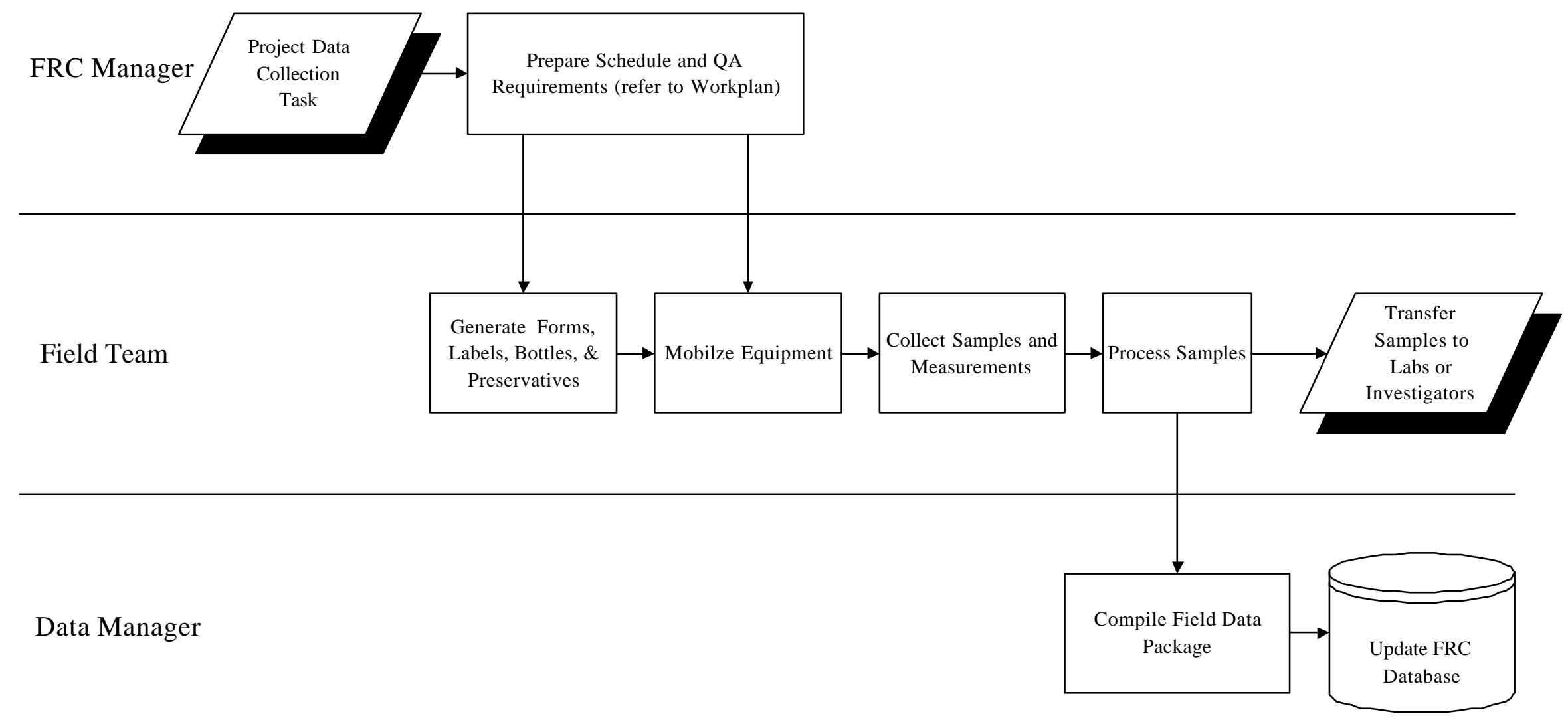

Figure 3.2. Field measurement and sampling activities. 
Any necessary field logs and measurement recording forms will be approved by the FRC Manager and provided to the Field Team prior to going into the field. The FRC Manager or approved designee will also notify the appropriate analytical laboratories of the upcoming sampling event, including the number of samples and analyses required. The Field Team will assemble the equipment necessary to support the sampling event. This equipment includes the containers and labels necessary to hold the samples collected.

Samples will be obtained according to procedures approved by the FRC Manager. Field quality control (QC) samples will be used as needed to assess the variability in executing procedures, making field measurements, and obtaining field samples. All QC samples will be allocated and shipped using the same procedures followed for the samples associated with them. Field QC samples will include, on an as needed basis, blanks, rinsates and duplicates as defined below. QC samples will be analyzed under the same analytical requirements as regular samples.

Trip blank: A trip blank is used only with samples to be analyzed for volatile organic contaminants if needed. Trip blank, consisting of a sealed container of organic -free water, will travel from the field to the laboratory with the samples to be analyzed.

Field rinsate (equipment blank): A field rinsate consists of a sample of final rinse water from the decontamination of field sampling equipment. Analysis of the field rinsate determines if the decontamination procedure is adequate to avoid carryover of contamination from one sampling location to another. Sampling equipment will be decontaminated as needed before use and after each sample is collected. The extent of decontamination will be commensurate with the potential effect of cross-contamination between samples.

Field blank: Field blanks will be collected as needed from each source water (distilled/deionized water) used for sampling equipment decontamination or for assisting well development procedures. Additional field blanks may be taken as necessary. Field blanks consisting of analyte-free rinse water or solvent will be brought to the field in sealed containers, opened and exposed to ambient conditions during sampling activities, closed, and transported back to the laboratory.

Field duplicate: A field duplicate, which consists of a duplicate sample from one location, indicates whether the field sampling technique is reproducible. Duplicate samples will be obtained for all sample matrixes as needed. Duplicate analyses will be performed for approximately 1 in 20 samples to ensure repeatability or as specified by the FRC Manager.

All field activities and measurements will be documented in sufficient detail to enable reconstruction of the events. Field measurements will be recorded on appropriate data forms. All data will be directly entered in the field, signed, and dated. If entry changes are made, one line will be drawn through the deletion, the entry changed, and the change signed and dated in the notebook or on the data form. Changes made to original notes will not obliterate the original information. Sufficient information will be provided to establish the reason for each change. Field calibration methods will be those recommended by the manufacturer for a given instrument. All documents associated with field sample collection will be retained in a field event file located in the FRC library. Selected information about the field samples will be entered into the FRC database as described in Section 5.

\subsection{PROCESSING AND DISTRIBUTION OF FIELD SAMPLES}

The processing and distribution of samples will be determined by the needs of the end user. Figure 3.3 illustrates the activities involved in this phase.

Processing may occur between sampling and sample distribution. For example, soil samples collected for 
microbial analysis may require additional processing prior to shipment under inert gas to minimize oxidative processes and decrease the opportunity for aerobic metabolism. In this case, after coring, the samples are passed though an airlock into an anaerobic glovebox where transfer to the appropriate storage container takes place. In addition, sampling equipment/containers may be steam cleaned and/or autoclaved and wrapped in clean plastic or foil before use to maintain aseptic conditions.

Samples will be preserved and stored as required by the analytical method and/or investigator's requirements. Storage on site may occur for short periods of time in ice chests containing "blue ice" but the sample will be quickly transferred to refrigerated storage at the appropriate temperatures. Prior to leaving the contaminated field site, a FRC health-physicist will check the sample containers for exterior radioactivity. Storage of contaminated samples will follow ORNL procedures applicable to radioactive materials.

Samples may be transferred to ORNL from the FRC site at Y-12 as long as the radiological contamination is below $70 \mathrm{~Bq} / \mathrm{g}$ total activity. Activity will be determined by process knowledge until higher activity is noted. At that time, samples will be transported and shipped according to updated process knowledge. Radioactive samples (exceeding $70 \mathrm{~Bq} / \mathrm{g}$ but less than Reportable Quantities) must be packaged and transported by Y-12 to ORNL with guidance from the ORNL Transportation and Packaging staff. Preserved samples and samples with dry ice may be transported to ORNL from Y-12 according to Materials of Trade (MOT) regulations.

Samples that are shipped offsite to a laboratory or NABIR investigator will be packaged and shipped in accordance with procedures described in a Memorandum of Understanding between ESD and the ORNL Transportation and Packaging Management (TPM) Organization. An offsite shipment is defined as any shipment made outside DOE property that is fenced or otherwise access controlled (suitable access control includes physical barricades, manned gate houses, or manned temporary positions). Samples that will be analyzed by an external laboratory within driving distance will be transported as a MOT, as defined in 49 CFR 171.8. Such samples may be transported by FRC staff in a DOE vehicle.

A sample tracking form will accompany each shipment transferred to an ORNL or contract analytical laboratory. This form lists the identifier, matrix, collection date and time, type, preservative, requested analysis, and processing for each sample in the shipment. Field rinsates and blanks will be designated as QC samples on the sample tracking form, so as not to be chosen for laboratory duplicates and spikes. The form also contains a signature section at the bottom that is used to document a sample transfer (i.e., chain of custody) to a contract analytical laboratory.

A sample request data sheet will accompany each shipment sent to a NABIR investigator. This form lists the sample request, investigator's name, information about the samples contained in the shipment, relevant field measurements, and shipping information. A copy of the radiological survey tag is also included for samples from the contaminated area.

Before shipment, each sample container will be visually inspected for indications of leaks or defects in the sample container. Sample containers will be wiped on the outside if necessary to remove any exterior contamination and packed to prevent breakage and/or leakage. The labeled and sealed sample containers will be placed in a waterproof metal (or equivalent strength plastic) ice chest or cooler for shipping. To prevent the sample containers from sliding around in the cooler, the cooler will be filled with inert cushioning material, such as bubble pack. The completed documentation (e.g., sample tracking form) will be placed inside the cooler lid. The lid will be secured with strapping tape by wrapping the cooler completely in a minimum of two locations.

Archived samples will be collected and maintained to provide for the needs of the principal investigators as well as 
site characterization. Several levels of archived samples may be maintained. Under some circumstances, backup samples may be kept to allow for shipment of a replacement sample if any samples are lost in shipping. Sample material archived for future microbial analyses may be maintained at $4^{\circ} \mathrm{C}$ or in a frozen state at $-80^{\circ} \mathrm{C}$ or lower depending on sample use. Bulk storage of soil or soil cores may also occur. Samples retained for long-term archival will be managed in compliance with Title 10 CFR Part 835 which establishes radiation protection standards, limits, and program requirements for protecting individuals from ionizing radiation resulting from the conduct of DOE activities. Storage areas will be posted and a list of archived samples will be maintained. 


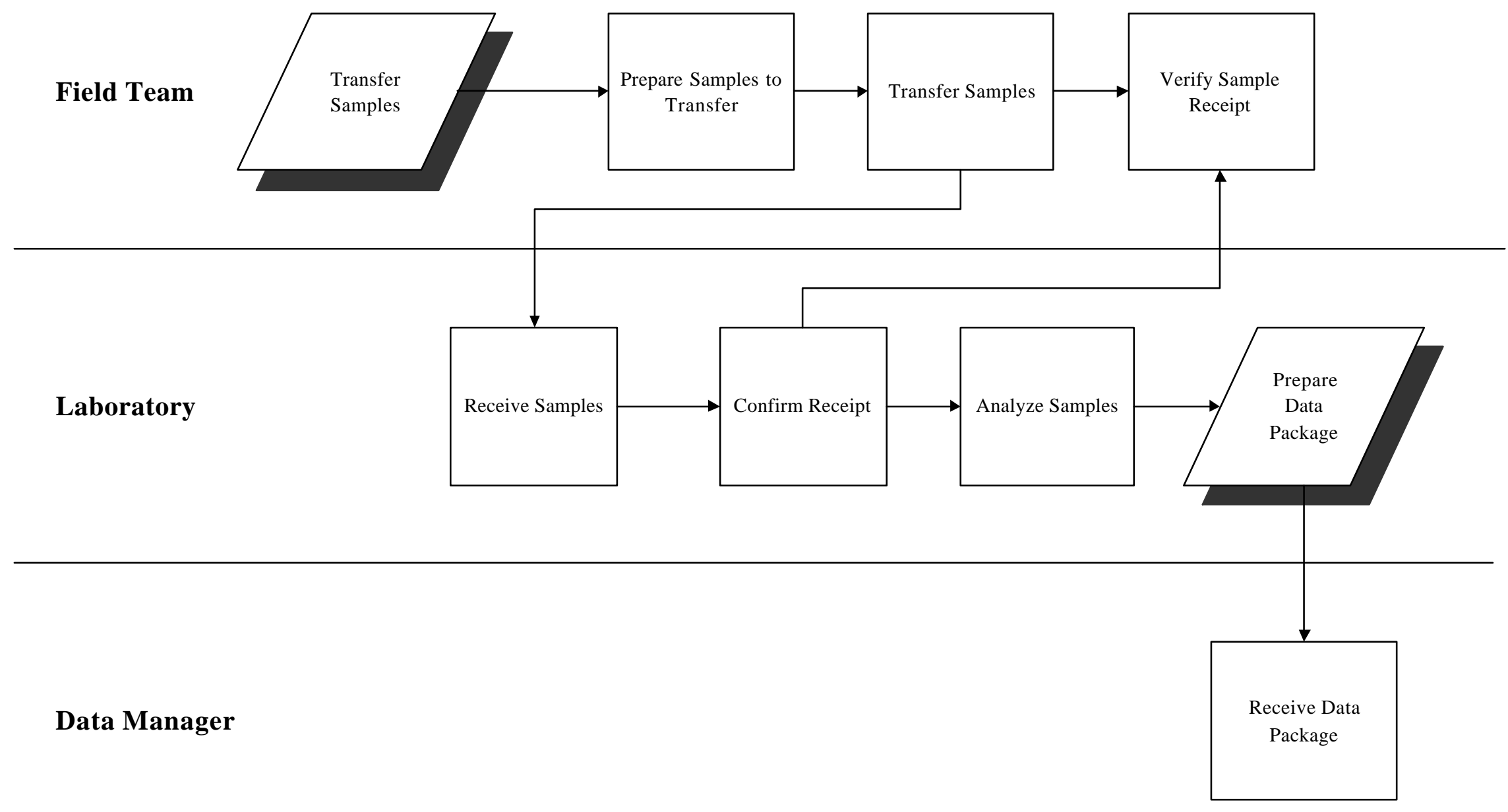

Figure 3.3. Sample distribution activities. 


\section{LABORATORY ANALYSES}

This section provides an overview of the activities associated with the laboratory analysis of field samples. Minimum requirements for analysis of FRC samples are summarized here. Additional requirements or exceptions to the minimum requirements will be communicated to the laboratory with a Statement of Work (SOW) or other appropriate documentation.

\subsection{ANALYSIS}

Upon receipt at the laboratory, the identification information on each sample is compared to the information contained on the accompanying sample tracking form. The laboratory will verify the number of samples received and will check the sample identifiers and requested analyses by comparing the tracking documents and the sample labels. The condition of the samples upon receipt will be checked against the required conditions and the results will be noted on the tracking documentation. The tracking form will be signed and dated by an authorized representative of the analytical laboratory, and a copy will be returned to the FRC Manager and placed in the FRC library. The laboratory will keep the original form until final disposition of the samples. A copy of the tracking documentation will also be included in the analytical data package prepared by the laboratory.

\subsubsection{Method Requirements}

If a specific analytical method is required by the FRC, then all associated sample holding times, detection limits and quality control requirements shall be adhered to unless exceptions are granted by the FRC Manager or designee. Sample preparation must ensure homogenization so that a representative aliquot is obtained for each analysis. Standards and reference materials must be stored separately from samples. Balances must be checked each day that they are used and must be calibrated annually by an independent source. Refrigerator temperatures will be spot checked on an ongoing basis.

\subsubsection{Instrument Calibration and Maintenance}

Instrument calibration is required to ensure that the analytical system is operating correctly and functioning at the sensitivity necessary to produce required detection limits and produce accurate sample quantitation. It also establishes the dynamic range of the instrument. Each instrument will be calibrated with standard solutions appropriate to the type of instrument and the linear range established for the analytical method.

The typical initial calibration sequence is an instrument blank and/or method blank, followed by a set of standards from the lowest concentration to the highest, which bracket the sample concentration. At least three levels of standard concentrations should be used. The initial calibration is verified with a mid-level standard, after every tenth sample and at the end of the analytical run. The standard results should agree with the initial calibration standard within $20 \%$ and with the preceding mid-level check within 10\%. Calibration will be redone when drift is suspected. Records of standard preparation and instrument calibration will be maintained. The analysis logbook, maintained for each analytical instrument, will include the date and time of calibration, the initials of the person performing the calibration, and the concentration of the calibration standard, as well as the analysis sequence of the samples and quality control samples.

All maintenance performed on an instrument should be documented in a maintenance logbook, which is kept with the instrument. The date, initials of the analyst performing the maintenance, and the type of maintenance should be recorded. Receipts from routine maintenance performed by the manufacturer's representative may be kept in folders and filed. 


\subsubsection{Standard/Reagent Preparation}

Standards are obtained either in their pure form, or in stock or working standard solutions. Dilutions are made from vendor standards. Standards are checked routinely for signs of deterioration (e.g., discoloration, formation of precipitates, and changes in concentration) and are discarded if deterioration is suspected. Standards are also verified with an independent check standard prepared from a source difference from the calibration standards initially and monitored weekly thereafter. All standards used for equipment calibration will be traceable to the U.S. Environmental Protection Agency, National Institute of Standards and Technology (NIST), or commercially available certified standard. Calibration standards are generally prepared using the same solvent used for sample preparation at the same concentration. Calibration standards are generally not subjected to the preparation (e.g., extraction, distillation, and digestion) process that is applied to the sample.

\subsubsection{Quality Control Samples}

A number of laboratory QC samples will be used to check sample preparation and analysis. QC samples will consist of blanks, duplicates, and spikes. Laboratory calibration and check standards will also function as QC components. Other types of quality control samples may be required by the specific analytical method. The FRC Manager or ASC will work with the laboratory analytical staff to determine an appropriate level of laboratory QC on a case by case basis. The typical laboratory analysis sequence should be calibration blank (instrument), method blank, calibration standards, method blank, 10 samples, check standard and/or mid-level calibration standard, calibration blank, samples. At the end of the analytical run, the mid-level calibration standard should be repeated. Laboratory duplicates and spikes are considered to be samples in the analytical sequence. Quality assurance procedures for laboratory processing will include at least one laboratory duplicate of a field sample per preparation batch or after each 20 samples to determine the precision of laboratory results. Potential laboratory QC samples include the following:

Method blank: A method blank is a blank sample made up of a pure, uncontaminated substance of the matrix of interest (usually distilled/deionized water or silica sand) that is subjected to all the sample preparation (e.g., digestion, distillation, extraction) and analytical methodology applied to the samples. The purpose of the method blank is to check for contamination from within the laboratory that might be introduced during sample analysis. A method blank should be analyzed whenever new reagents are used, with each batch of samples processed for analysis, and after any sample with a concentration greater than that of the highest standard or that might result in carryover from one sample to the next.

Calibration/continuing calibration blank (instrument blank): A calibration blank is the substance that is used to zero the instrument. The calibration blank is composed of the solvent used for the preparation of calibration standards and samples. The calibration blank accounts for any interference from the solvent matrix. A calibration blank should be analyzed before and after each set of standards.

Laboratory duplicate: The purpose of a laboratory duplicate is to check the precision of the analyst, the sample preparation methodology, and the analytical methodology. A laboratory duplicate is prepared by the laboratory analyst for each batch and is obtained by homogenizing a sample as thoroughly as possible and taking two separate aliquots of that sample for analysis. The duplicate sample, however, should never be a method blank, rinsate blank, trip blank, or a field blank. Generally, approximately 5 percent of the samples should be analyzed in duplicate. 
Matrix spike (or recovery of known additions): A matrix spike is a sample to which a known concentration of the compounds of interest has been added. The matrix spike is subjected to the same sample preparation and analytical methodology applied to the samples. The sample to be spiked is selected by the laboratory; however, the spiked sample cannot be an identified method blank, trip blank, or field blank. The purpose of the matrix spike is to check for interference or false readings caused by the sample matrix. The sample matrix effect is measured by calculating the percent recovery of the compounds added to the sample. Generally, five percent (5\%) of the samples should be analyzed using known additions.

Blank spike/laboratory control sample/check standard: The blank spike, or laboratory control sample, is a blank sample (usually distilled/deionized water or silica sand) to which a known concentration of the compounds of interest has been added. The blank spike is subjected to the same sample preparation and analytical methodology applied to the samples. The purpose of the blank spike is to check the accuracy of the analyst, the sample preparation methodology, and the analytical methodology. The level of accuracy is measured by calculating the percent recovery of the compounds added to the sample.

\subsection{DATA REPORTING}

When the analyses are completed, the laboratory will prepare the data package and, where appropriate, an electronic data deliverable (EDD). Analytical and quality control data will be presented in tabular format whenever possible. Blank corrections (e.g., field blank, trip blank, method blank) are not allowed. All entries and corrections must be made in indelible ink with a single line drawn through errors and changes initialed and dated by the individual making the changes. All sample tracking forms and pertinent shipping information, as applicable, shall be included in the data package. All results shall be expressed in the significant figures and units required by the SOW. Information presented will include:

- Sample identification number used by the laboratory and/or the sample identification provided if different from that used in the laboratory;

- Date sample was received, prepared, and analyzed;

- Dilution factors;

- Analytical method used;

- Instrumentation type, manufacturer, model and year;

- Chemical parameters analyzed, reported values, data qualifiers, and units of measurement;

- Method detection limit of the analytical procedure;

- Results of QC sample analysis;

- Analyst;

- Data approver if different than the analyst.

The data package and EDD will be sent to the Data Manager.

\subsection{SAMPLE DISPOSAL}

Waste generated by analytical laboratories must be disposed of according to applicable state and federal regulations. Laboratory waste cannot be returned to the FRC for disposal. Requests for return of unused FRC samples may be made directly to the FRC Manager. Additional information about waste disposal can be found in the FRC Management Plan (Watson and Quarles 2000a). 


\section{DATA MANAGEMENT}

This section provides an overview of the activities associated with managing and delivering the field and laboratory generated by the FRC. The activities involved in this phase are summarized in Figure 5.1.

\subsection{PROCESS FIELD DATA}

Processing field data includes receiving the field data collection package and processing it to make the data available for use. The Field Team leader, as designated by the FRC Manager for each sampling event, is responsible for making sure that the field data package is delivered to the Data Manager. Information recorded during the processing of the field data will document the completeness of the data and will provide a record of any modifications made to the field data.

The field data package will contain the forms that the field data were recorded on, and sample tracking, site information, and downloaded data logger data, as applicable. Each field data package will be added to the FRC library. Selected field data received in hard copy format will be computerized. The data will be entered using double data entry or single entry with verification. Field data received in electronic form, such as data loggers, will be processed using programs that are designed for use with the specific equipment. Problems in the documentation or content that are uncovered in the processing of the field data will be resolved through the Field Team leader and documented in the field data package.

\subsection{PROCESS LABORATORY ANALYTICAL DATA}

Each laboratory analytical data package will be delivered to the Data Manager. The Data Manger will review the data package for completeness and legibility. Data received only in hard copy format will be computerized via double entry or single entry with verification.

If the laboratory prepares an EDD, it will also be sent to the Data Manager. Each EDD will be scanned for viruses before the deliverable is processed. The EDDs will be read and processed with the appropriate computer software. The contents of the EDD will be verified against the hard copy data package. If any problems are found with the data, either in hardcopy or electronic form, the Data Manager will notify the laboratory representative to coordinate the resolution of the problems. Documentation of the problem and resolution will be added to the data package.

\subsection{REVIEW DATA}

Data will be reviewed before it is provided to NABIR investigators. The review process determines whether a set of data satisfies the characterization requirements. This process requires the integration and evaluation of all relevant information associated with either a field or laboratory measurement. The data reviewer will generally be the investigator responsible for the technical implementation of the data collection activities. The reviewer will typically evaluate the data to assess its reasonableness as compared with (1) the conceptual understanding of the system, (2) data from similar sites, (3) historical data from the same site, and (4) other criteria based on the reviewer's professional judgement. 


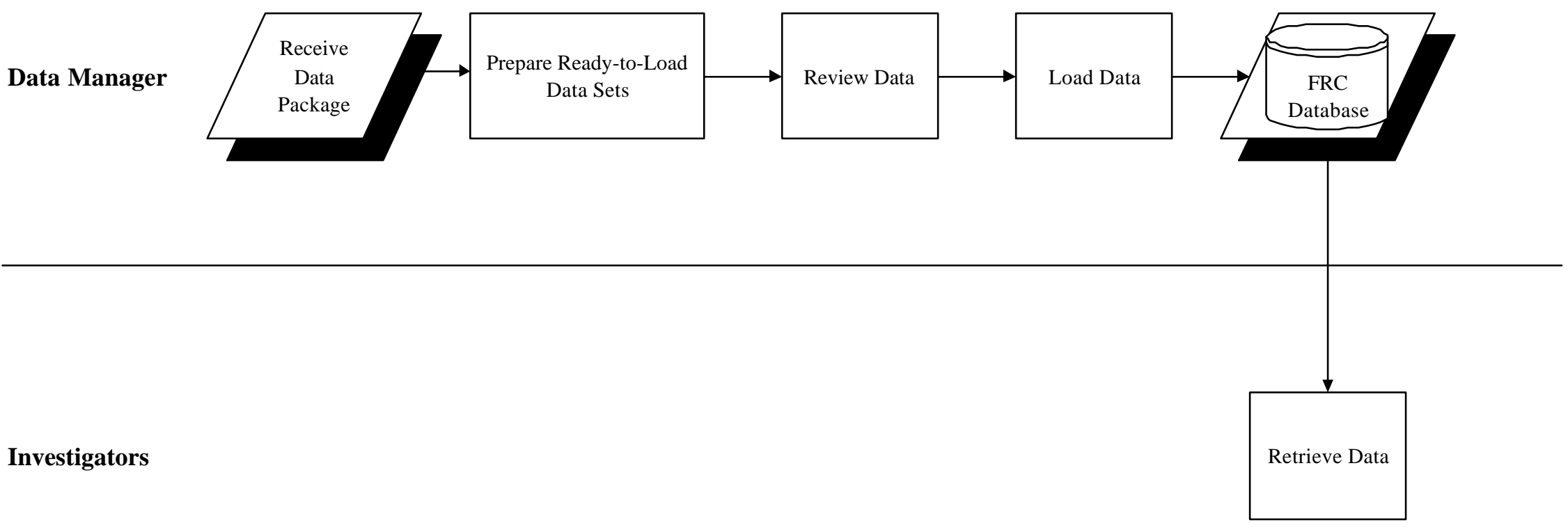

Figure 5.1. Data management activities. 
Outlier and range checking will be conducted as needed to identify suspect values. A variety of graphical and statistical summaries may be used such as box-and-whisker plots, stem-and-leaf plots, and time-series graphs. The data reviewer will also perform reasonableness checks on the data based on a scientific and historical understanding of the system from which the data were obtained. Various checks will be conducted, such as comparing $\mathrm{pH}$ and alkalinity values, calculating charge balances, comparing filtered and unfiltered measurements, and analyzing frequency distributions of measurements.

If the reviewer finds extreme or suspect values, the reviewer will investigate these values to determine if they are accurate or due to a problem in sampling, analysis, or data reporting. The reviewer may also assign qualifiers to the measurements to denote the usability of the data.

\subsection{PROVIDE DATA TO NABIR INVESTIGATORS}

Important site characterization data will be provided to NABIR investigators via the FRC web page (http://www.esd.ornl.gov/nabirfrc/). These data will typically be available as text files or spreadsheets. The Data Manager will work with the Field Teams and analytical laboratories to ensure an orderly and timely posting of relevant data to the web page. In addition to the data, information describing the data sets (metadata) will be available. Investigators who receive samples from the FRC should submit their analytical data to the FRC Data Manager. Data sets that are too large to place on the web page (e.g., water level files collected with data loggers and transducers) will be archived. However, descriptions of these data will be placed on the web page so that NABIR Investigators can determine if they would like copies of the data delivered to them. 


\section{ASSESSMENT AND OVERSIGHT}

\subsection{MANAGEMENT ASSESSMENT}

Management assessment of characterization activities shall be performed continuously through meetings with FRC staff, feedback from personnel including matrix organizations such as health physics and waste management, and technical review of the samples and data produced as part of the FRC program. These assessments will be documented through meeting minutes, electronic mail or memos.

\subsection{INDEPENDENT ASSESSMENT}

The primary form of independent assessment will be sponsor reviews of FRC performance. Personnel from the DOE Office of Science will provide continual information on how the FRC meets their expectations through periodic meetings, electronic mail, conference calls, technical document and data reviews and/or workshops.

Another important component will include feedback or survey information collected from researchers who use the FRC. Information collected from these sources will be used to continuously improve sponsor and user satisfaction. Other internal independent assessment activities consist of peer review by the Field Research Advisory Panel (FRAP) of technical processes.

\subsection{CORRECTIVE ACTION}

Corrective action for findings related to characterization activities will be determined by the FRC Manager or designee with input from the DOE sponsor and the FRAP. The FRC Manager will document these corrections.

\subsubsection{Nonconformance}

An individual discovering nonconforming characteristics for services, purchased items, process parameters, or other substandard conditions related to an FRC activity will document the problem and bring it to the attention of the FRC Manager.

\subsubsection{Variances}

When a deviation to established plans, procedures, or work documents is required due to unanticipated events related to the research goals of the FRC is identified, it is the responsibility of the person performing the work to obtain the approval of the FRC Manager or designee before initiation of the activity.

\subsection{LABORATORY PERFORMANCE INDICATORS}

Laboratories supporting the FRC must participate in a QC program that serves to qualify the analytical methods used for FRC samples and the analytical personnel performing those methods. For external laboratories, blind sample programs may consist of nationally recognized programs such as the DOE's Environmental Measurements Laboratory and Multi-analyte Performance Evaluation Program. Frequencies of blind sample analysis depend upon the availability of the blind sample program and the sample throughput of the laboratory. For laboratories internal to ORNL, performance will be judged by one or more of the following: technical peer review, analysis of 
independent check standards, verification of check standard results by an independent system, feedback from other program sponsors, or comparison with historical data. 


\section{OPERATIONAL SUPPORT}

\subsection{PROCEDURES/DOCUMENTS}

Documents prepared for use in FRC activities include a Management Plan, Site Characterization Plan, Health and Safety Plan, forms, QAP, and work aids, as applicable. The preferred distribution for FRC documents is via the FRC web site (http://www.esd.ornl.gov/nabirfrc/). Documents will be formatted to be retrievable by the intended users from the FRC web site, usually as html or pdf. The latest revision will be maintained on the web site, with earlier versions kept in backup storage, either hardcopy or electronic media. The status of the document (i.e. draft or final) will be listed as well as the revision date. If approval signatures are required, a signed hardcopy will be maintained in the FRC library.

Work aids will be developed only when actions must be controlled to assure the success of the activity, in terms of personnel effort and cost. The following questions may be used as a guide to decide whether a work aid is needed:

Is the activity repetitive, and must it be performed the same way each time, and/or performed by multiple individuals?

Is the activity unique and complicated, infrequent or unusual?

Could the failure of the activity incur a substantial expense or loss of critical data, or create a safety hazard?

Work aids should include the purpose, scope, action steps, date written and signature of the author.

\subsection{FIELD AND SAMPLE DATA RECORDS MANAGEMENT}

Field and sample data records related to FRC characterization activities will be stored in the FRC Library and/or electronically at the FRC in a project database, as specified by the FRC Manager. Computer files will be backed up to tape, diskette, or removable drives at least once per week. The backup will be stored in a secure location.

\subsection{COMPUTER HARDWARE AND SOFTWARE}

Software that is developed for the FRC shall be verified for accuracy using representative test cases. The results of these tests shall be documented and filed. Programs and spreadsheets for handling data will be routinely backed up. Spreadsheets are considered applications of software. It is the responsibility of the spreadsheet creator to ensure the spreadsheet is performing calculations correctly.

\subsection{PROCUREMENT}

ORNL requirements apply to all FRC procurements. Items and services are selected based on vendor provided information. Whenever possible, items are procured from vendors of known quality and service. It is the responsibility of the requestor to ensure purchased items can meet their intended use and to obtain appropriate certificates of conformance or analysis. 
Control of subcontractor services rendered for the FRC shall adhere to requirements described in ORNL procurement procedures and the ESD Subcontracting Process. Subcontractors involved with characterization activities are responsible for adhering to company policy and QA/QC requirements of the FRC and sample requestor.

\subsection{MEASURING AND TEST EQUIPMENT}

The FRC designates equipment as measuring and test equipment (M\&TE) according to the definition: "A graded approach is encouraged such that equipment essential to safety-systems, environmental-permitted systems, security system, or other mission essential operations will be considered M\&TE. Similar equipment used for research or operations that fall outside of the applications above may be considered as not M\&TE and userchecks, commensurate in formality with the application and/or as recommended by the manufacturer, are appropriate. For analytical laboratory (and similar) operations user validation by certified or approved trained operators is allowed as defined in appropriately approved quality or operating plans and procedures." Commensurate with this definition, the FRC does not designate analytical instrumentation that is either user calibrated or calibrated by the supervising analyst as M\&TE. Equipment that requires calibration at specified intervals by an external organization or by a non-user is designated as M\&TE (e.g., analytical balances calibrated by the ORNL calibration organization). Calibration of M\&TE will be in accordance with the requirements of the calibration organization. To prevent the inadvertent use of equipment that cannot be calibration verified as required, the equipment is either tagged out of service or the problem is communicated to the FRC Manager. 


\section{REFERENCES}

These documents are available on the Web sites listed below. Hardcopy documents may be requested from the FRC Manager.

DOE-ER-STD-6001-92. Implementation Guide for Quality Assurance Programs for Basic and Applied Research.

DOE/ER-0659T. 1995. NABIR Program Plan. U.S. Department of Energy, Washington, DC.

(http://www.er.doe.gov/production/ober/nabir/contents.html)

Environmental Sciences Division Quality Assurance Program

(http://home.ornl.gov/divisions/environmental_sciences/ornl-internal/quality.htm)

Environmental Sciences Division (ESD) Operating Procedures

(http://home.ornl.gov/divisions/environmental_sciences/esd-internal/procedures/ESD-04.html)

ESD-01. Control of Web-Based Documents

(http://home.ornl.gov/divisions/environmental_sciences/esd-internal/procedures/ESD-01.html)

ORNL Standards-Based Management System

(http://eshtrain.ct.ornl.gov/sbms/sbmsmain.html)

Watson, D.B. and H.D. Quarles. 2000a. Natural and Accelerated Bioremediation Research (NABIR) Field Research Center (FRC) Management Plan. ORNL/TM-2000/267. Oak Ridge National Laboratory, Oak Ridge, TN. September 2000; revised April 2001.

(http://www.esd.ornl.gov/nabirfrc/other/fremp.pdf)

Watson, D.B. and H.D. Quarles. 2000b. Site-Specific Health and Safety Plan for Work Activities at the Natural and Accelerated Bioremediation Research (NABIR) Field Research Center (FRC), Oak Ridge, Tennessee. ORNL/TM-2000/264. Oak Ridge National Laboratory, Oak Ridge, TN. August 2000. (http://www.esd.ornl.gov/nabirfrc/other/frchsp.pdf)

Watson, D.B., G.R. Moline, P.M. Jardine, S.K. Holladay, T.L. Melhorn, B. Gu, A.V. Palumbo, B.P. Spalding, C.C. Brandt, and W.E. Doll. 2000. Natural and Accelerated Bioremediation Research (NABIR) Field Research Center (FRC) Site Characterization Plan. ORNL/TM-2000/269. Oak Ridge National Laboratory, Oak Ridge, TN. September 2000; revised April 2001.

(http://www.esd.ornl.gov/nabirfrc/other/scp.pdf)

Wolfe, A.K., D.J. Bjornstadt, and D.B. Watson. 2000. Communication Strategy for the U.S. Department of Energy Natural and Accelerated Bioremediation Reserach (NABIR) Field Research Center (FRC). Oak Ridge National Laboratory, Oak Ridge, TN. May 2001.

(http://www.esd.ornl.gov/nabirfrc/other/csp.pdf) 


\section{INTERNAL DISTRIBUTION}

1. S. G. Hildebrand, 1505, MS-6037

2-4. ESD Library

5. ORNL Central Research Library

6. ORNL Lab Records-RC

\section{ELECTRONIC DISTRIBUTION}

7. C. C. Brandt, 1505 , MS -6038

8. S. K. Holladay, 1505, MS 6038

9. D. B. Watson, 1505 , MS-6038 